\title{
STUDIES MADE BY SIMULATING SYSTOLE AT NECROPSY. III. ON THE GENESIS OF THE SYSTOLIC WAVES OF THE BALLISTOCARDIOGRAM ${ }^{1}$
}

\author{
By ISAAC STARR AND TRUMAN G. SCHNABEL, JR. ${ }^{2}$
}

(From the Department of Therapeutic Research; and from the Robinette Foundation, Medical Division, of the Hospital of the University of Pennsylvania, Philadelphia, Pa.)

(Submitted for publication June 19, 1953; accepted September 18, 1953)

In a previous communication experiments have been described (1) in which, when systole was simulated in cadavers, the size of the ballistocardiogram proved to be dependent on two major factors : First, on the energy of the systolic blow; and second, on a factor which may be thought of as determining the hardness or softness of the blow, a factor varied in our experiments by changing the padding on the mallet whose strokes provided the energy for the simulation of systole. In this paper we seek to unite these two major factors in the genesis of the ballistocardiogram into a single conception and to ascertain its relation to more familiar aspects of cardiac function. Put another way we have asked ouselves the question whether there is a single aspect of cardiac performance which is driving the ballistocardiogram and if so, how changes in that aspect are related to changes in the size of this record.

In making this study we shall take full advantage of the curves which record both cardiac output and blood pressure at each instant, which are the chief features of our experimental preparation, and which permit us to estimate many aspects of "cardiac" performance with an accuracy not as yet approached in measurements made on living men or animals. In this paper we will present our data in detail. The results show that there is indeed a single aspect of cardiac function, related to the heart's force, so closely correlated with the amplitude of the ballistocardiogram under such a great variety of conditions that the magnitude of the one can properly be thought of as determining that of the other.

\section{EXPERIMENTS}

The apparatus is shown in Figure 1. It and the conduct of the experiments have been described in detail

1 This work was supported by a research grant from the National Heart Institute of the National Institutes of Health, United States Public Health Service.

2 Markle Scholar in Medicine.
$(1,2)$. The results to be presented here were secured by simulating systole in cadavers lying on a ballistocardiograph. All the experiments but one were performed between 3 and 12 hours after death; one, through an error, was performed 24 hours after without any noteworthy difference in result. Normal or abnormal diastolic pressure levels were secured by an infusion of blood into the femoral artery, which was terminated just before systole. Systole was simulated by driving blood into the aorta and pulmonary artery by a blow from a heavily padded mallet falling through a known arc, which forced in the pistons of the two syringes.

Both peripheral and central blood pressures were measured continuously by Lilly capacitance manometers (3) while "cardiac output" at each instant of systole was registered by a record of the position of the syringe pistons made by a slit and light beam system.

Occasionally this technique was varied. In systoles No. 10 and 11 on $\mathrm{J}$. W., to get widely diverse cardiac ejection curves, the syringes were pushed in by hand instead of by a blow from the mallet. In systoles No. 2 and 3 in M. M., blood pressure was measured in the pulmonary artery instead of the aorta. Figure 2 gives typical examples of the types of records secured.

In the conduct of the experiments we sought great diversity. Thus the stroke volume varied from 69 to $23 \mathrm{cc}$., the duration of ejection corresponded to that of pulse rates ranging from 200 to 30 per minute, the blood pressure varied from a systolic of 198 and a diastolic of 114 $\mathrm{mm}$. $\mathrm{Hg}$ to a systolic of 52 and a diastolic of 29 ; some subjects showed advanced arteriosclerosis while in others the vessels were normal. We were also at pains to produce great variation in the contour of the cardiac ejection curves.

\section{MEASUREMENTS AND CALCULATIONS}

Blood pressure, pulse wave velocity, duration of ejection, and ballistocardiograms were estimated from measurements made from the photographs with a millimeter rule and a right angle placed directly on the records; the slopes of the syringe ejection curves were measured by an angle protractor as is shown in Figure 3. Every measurement was checked by remeasurement long after the result of the first had been forgotten, and we finally convinced ouselves that making the readings under magnification did not improve our accuracy.

The two authors checked the accuracy of their measurements against each other. In measuring the slopes 


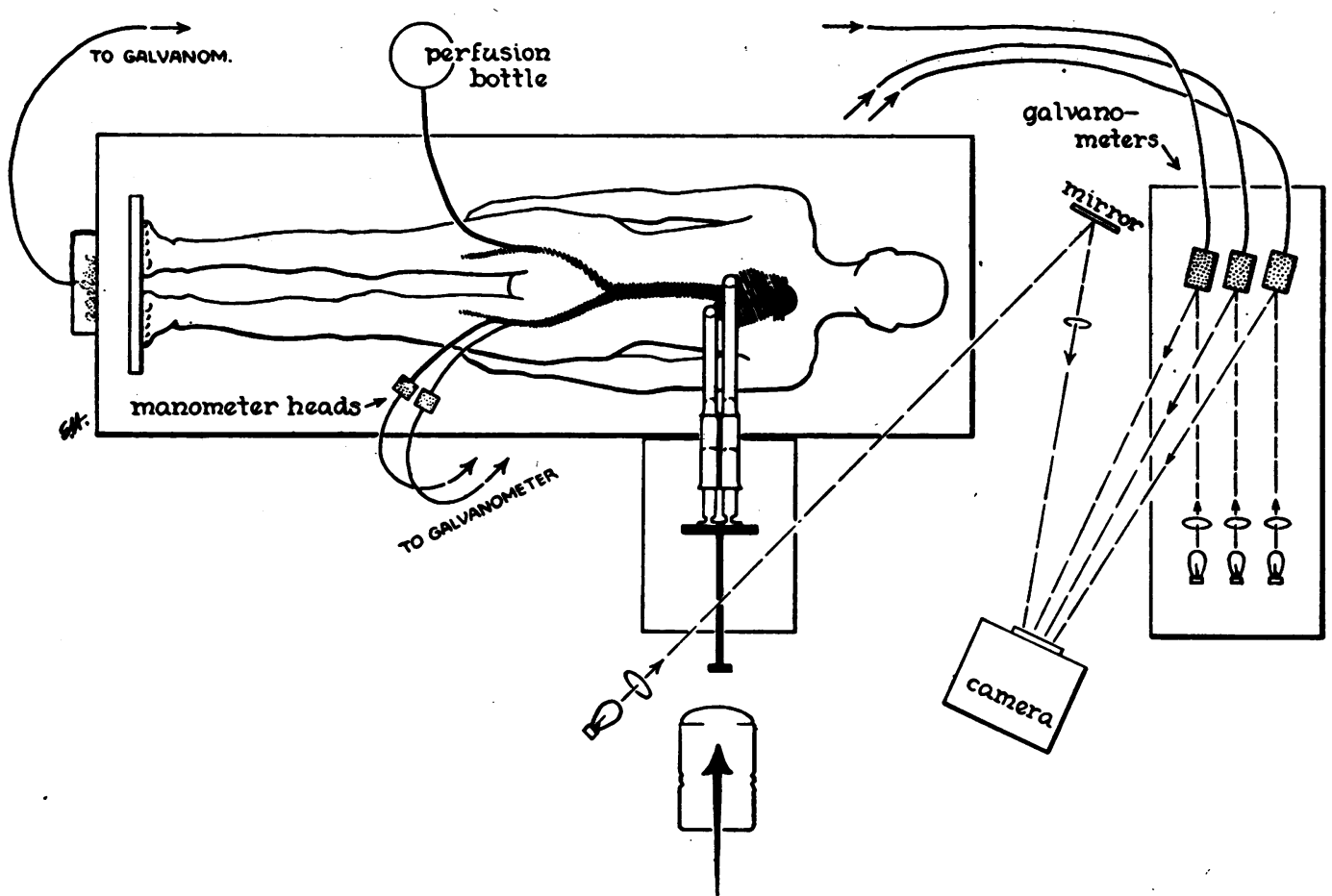

Fig. 1. General Arrangement for Simulating Systole in a Cadaver Lying on a BALLISTOCARDIOGRAPH

The details of the apparatus have been described $(1,2)$ and a drawing showing the apparatus as viewed from the side has also been published (1).

In brief: The suitably curved glass cannulas shown are of large diameter and their tips are tied into the mouths of the aorta and pulmonary artery. Glass tubes of similar size connect these cannulas with the syringes. The heavily padded mallet is suspended from an axis by a long handle which, at right angles to the plane of the figure, cannot be shown in it. Systole is simulated by letting this mallet fall through a known arc and its blow drives in both the syringe pistons and the slit which records their position: however, blows strong enough to completely empty the syringes are never used so the amount of blood injected varies with the conditions of each experiment. Blood pressure is recorded in two places (usually in the arch of the aorta and femoral artery as shown, sometimes in the pulmonary artery) by two Lilly manometers attached to minute plastic tubes inserted into the vessel through needles and advanced until their tips were in the desired position. The manometers and the ballistocardiograph are connected with mirror galvanometers and records are made by light beam systems and a photokymograph. The perfusion bottle attached to a cannula in the femoral artery is elevated at different distances above the cadaver and so perfusion from it provides any desired "diastolic" pressure before each "systole" is delivered.

of the steepest part of our cardiac ejection curves, where it was important to our thesis to get as high accuracy as possible, the authors reading the angles independently seldom differed by more than 1 and never by more than $2^{\circ}$. When measuring distances used in estimating blood pressure, pulse wave velocity, wave durations etc., they usually agreed within $0.3 \mathrm{~mm}$., a distance which corresponded to about $1 \mathrm{~mm}$. $\mathrm{Hg}$ pressure and $0.006 \mathrm{sec}$. time.

We were content to read the ballistocardiogram wave amplitudes to the nearest millimeter and the readings were corrected to a standard displacement of $1 \mathrm{~cm}$. for 280 grams force. The decimal points which appear on the tables are due to this correction.

The total stroke volume was measured both from the change in the record and by reading the scale on the syr- inges before and after each systole. These values seldom differed by more than $2 \mathrm{cc}$. Duplicate readings of the syringe scale often differed by $1 \mathrm{cc}$.

For purposes of reproduction in one place the curves of cardiac output at each instant of systole were magnified 2.5 times and transposed to coordinate paper by a pantograph. These transposed curves were brought together on a single sheet by tracing them over a strong light. After inking the curves with the aid of a flexible ruler, they have been reproduced as Figure 4. However, all measurements of the slopes of the curves were made from the original records, rather than from the enlargements, which suffered some distortion in the process.

The statistical analysis of the data was performed with 

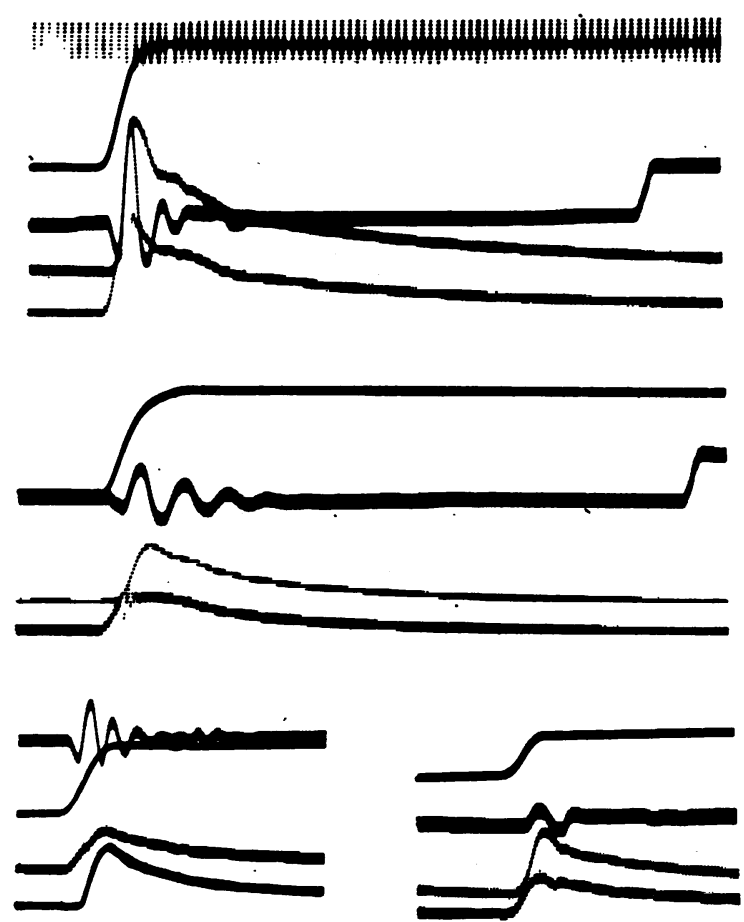

Fig. 2. From Typical Records of Simulated Systoles in Cadaver Preparations

Top. Systole No. 6 on cadaver H. Z. Time is at the top, the shortest interval $0.04 \mathrm{sec}$. The record next below is that of the movement of the syringe pistons and so of the cardiac output. Next record below is the ballistocardiogram, the systolic deflections are shown towards the left; its calibration, the deflection carried by the removal of a force of 280 grams, is at the extreme right. The next record is femoral blood pressure, the bottom record aortic blood pressure; their calibrations are not reproduced.

Middle. Systole No. 1 on M. L. The film speed is identical with that of the top record. The cardiac output record and the ballistocardiogram, which could be readily distinguished in the original photograph, are superimposed at the left; again the ballisto calibration is seen at the extreme right. The femoral blood pressure, record is above the aortic.

Bottom left. Systole No. 8 on J. W. Time is not shown and film speed was similar to the top record. The ballistocardiogram is above the cardiac output record. The aortic pressure record is above the femoral.

Bottom right. Systole No 13 on $\mathrm{H}$. Z. Time as in the top record. The records are in the same order, from above downward, as in the top record.

In all records the correction required for alignment is negligible. The reproductions are $\%$ actual size.

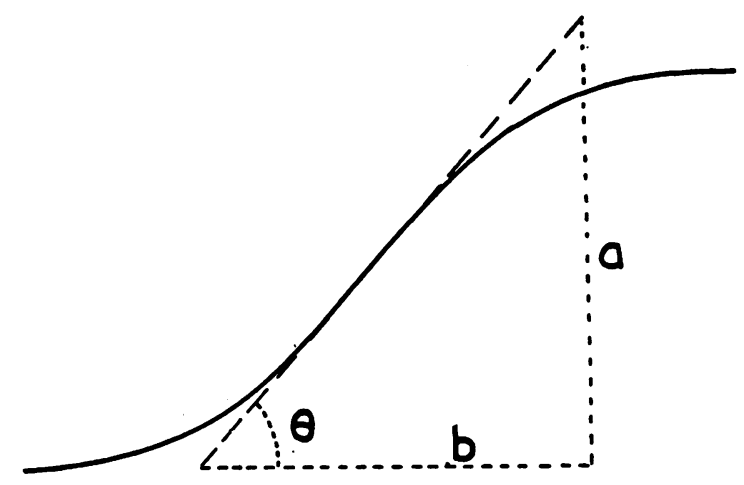

Fig. 3. Method of Measuring Maximum Slope of Cardiac Output Curves

The angle protractor straight edge was placed to coincide with the maximum slope and the angle with the horizontal, $\theta$, was measured. Its tangent, the ratio $a / b$, was obtained from standard tables. The maximum velocity in cc. per sec. was secured by applying the calibration of the cardiac output record to the vertical component, $a$, and that of the time record to the horizontal component, $b$.
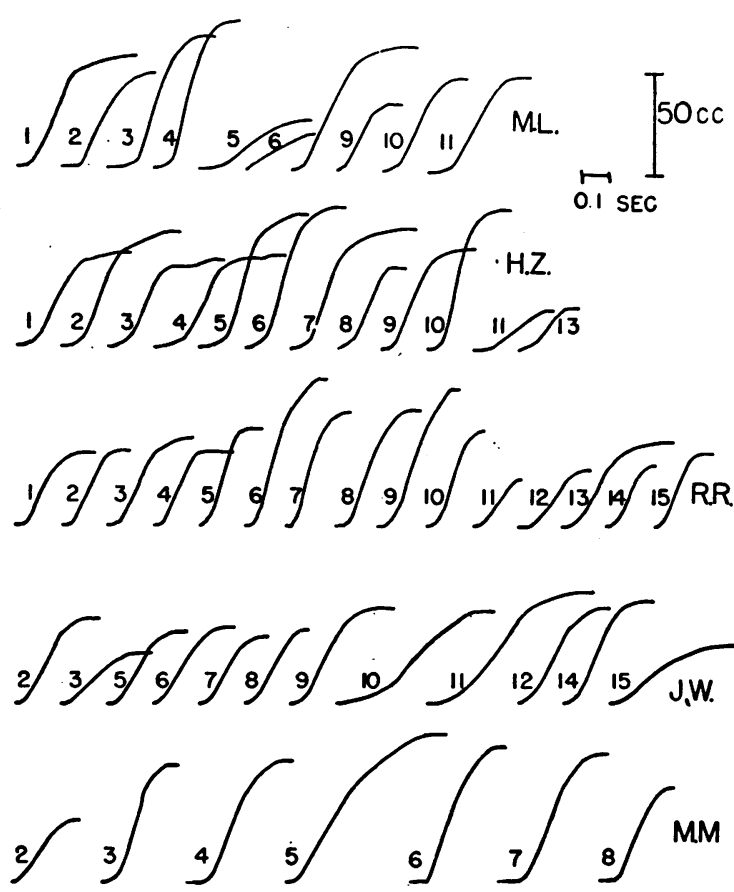

Fig. 4. Curves of Cardiac Ejection during Systole

The numbers correspond to the systoles as numbered in the tables and the curves of each subject have been placed in a row and can be identified by the initials placed after the last curves. The calibrations for cardiac output and for time are in the upper right corner, and apply to all the curves. The reproductions are $\%$ the size of the original curves. 
TABLE I

Data from experiments on $M . L$.

\begin{tabular}{|c|c|c|c|c|c|c|c|c|c|c|c|c|c|c|c|}
\hline \multirow{3}{*}{$\begin{array}{c}\text { Curve } \\
\text { no. }\end{array}$} & \multirow{3}{*}{$\begin{array}{c}\text { Systolic } \\
\text { blow }\end{array}$} & \multirow{3}{*}{$\begin{array}{l}\text { Padding } \\
\text { number }\end{array}$} & \multirow{2}{*}{\multicolumn{2}{|c|}{ Aortic B.P. }} & \multirow{2}{*}{\multicolumn{2}{|c|}{ Femoral B.P. }} & \multirow{3}{*}{$\begin{array}{l}\text { Stroke } \\
\text { volume }\end{array}$} & \multirow{3}{*}{$\begin{array}{l}\text { Duration } \\
\text { of eject. }\end{array}$} & \multirow{3}{*}{$\begin{array}{c}\text { Pulse } \\
\text { wave } \\
\text { velocity }\end{array}$} & \multicolumn{6}{|c|}{ Ballistocardiograms } \\
\hline & & & & & & & & & & \multicolumn{2}{|c|}{ I Wave } & \multicolumn{2}{|c|}{ J Wave } & \multicolumn{2}{|c|}{ K Wave } \\
\hline & & & Syst. & Dias. & Syst. & Dias. & & & & Size & Dur. & Size & Dur. & Size & Dur. \\
\hline $\begin{array}{r}1 \\
2 \\
3 \\
4 \\
5 \\
6 \\
8 \\
9 \\
10 \\
11\end{array}$ & $\begin{array}{c}\text { ergs } \times 10^{-6} \\
14.8 \\
14.8 \\
32.8 \\
32.8 \\
5.2 \\
5.2 \\
14.8 \\
14.8 \\
14.8 \\
14.8\end{array}$ & $\begin{array}{l}2 \\
2 \\
2 \\
2 \\
2 \\
2 \\
2 \\
2 \\
2 \\
2\end{array}$ & \begin{tabular}{|c|}
$m . \mathrm{Hg}$ \\
104 \\
89 \\
107 \\
110 \\
81 \\
67 \\
67 \\
165 \\
110 \\
100
\end{tabular} & \begin{tabular}{|c|}
$m . H g$ \\
60 \\
52 \\
57 \\
57 \\
67 \\
54 \\
27 \\
116 \\
76 \\
72
\end{tabular} & \begin{tabular}{|c|}
$m . H g$ \\
104 \\
94 \\
118 \\
118 \\
86 \\
75 \\
70 \\
172 \\
121 \\
109
\end{tabular} & \begin{tabular}{|c|}
$m . \mathrm{Hg}$ \\
55 \\
47 \\
57 \\
57 \\
69 \\
60 \\
29 \\
114 \\
79 \\
69
\end{tabular} & $\begin{array}{l}c c . \\
61 \\
54 \\
63 \\
69 \\
24 \\
18 \\
62 \\
38 \\
46 \\
48\end{array}$ & $\begin{array}{l}\text { sec. } \\
0.45 \\
0.36 \\
0.28 \\
0.24 \\
0.46 \\
0.32 \\
0.49 \\
0.30 \\
0.32 \\
0.35\end{array}$ & $\begin{array}{c}\text { m. per sec. } \\
5.1 \\
5.1 \\
4.6 \\
4.9 \\
5.0 \\
4.1 \\
3.8 \\
8.8 \\
4.6 \\
5.6\end{array}$ & $\begin{array}{c}m m . \\
2.4 \\
1.7 \\
3.3 \\
4.4 \\
0.9 \\
0 \\
2.5 \\
0.8\end{array}$ & $\begin{array}{c}\text { sec. } \\
0.09 \\
0.08 \\
0.08 \\
0.08 \\
0.08 \\
0.08 \\
0.08\end{array}$ & $\begin{array}{r}m m . \\
5.6 \\
7.8 \\
9.2 \\
11.6 \\
2.7 \\
2.6 \\
7.5 \\
5.1\end{array}$ & $\begin{array}{l}\text { sec. } \\
0.12 \\
0.11 \\
0.11 \\
0.10 \\
0.10 \\
0.10 \\
0.13 \\
0.12\end{array}$ & $\begin{array}{r}m m . \\
4.8 \\
6.1 \\
7.5 \\
10.7 \\
2.7 \\
0.9 \\
5.0 \\
3.4\end{array}$ & $\begin{array}{l}\text { sec. } \\
0.11 \\
0.10 \\
0.12 \\
0.13 \\
0.12 \\
0.10 \\
0.11 \\
0.09\end{array}$ \\
\hline
\end{tabular}

the aid of a Marchant calculator, using standard methods (4).

\section{MATERIAL}

The main characteristics of these subjects should be presented here, though they have been given in more detail before (1). M. L., a woman of 43 , weight 70 kilos, died of leukemia; there was a mild degree of atheroma of the great vessels. H. Z., a man of 67 , weight 74 kilos, died of cardiac infarction, and had moderate arteriosclerosis. R. R., a woman of 74 , weighed 49.5 kilos and died of carcinoma of the colon; there was marked widespread arteriosclerosis. J. W., a woman of 68 , weight 43 kilos, died of carcinoma of the sigmoid; there was widespread arteriosclerosis. M. M., a man of 43, weight 98 kilos, died of myelogenous leukemia; the arteries were judged to be normal. None of these subjects had hypertension during life.

\section{RESULTS}

In Tables $\mathrm{I}$ to $\mathrm{V}$ inclusive are the results secured in 54 consecutive systoles performed on the five cadavers perfused with blood. The numbers given to these systoles in the tables are not always consecutive because various calibrations were also given numbers, and the record of an occasional systole was lost through failure of the camera shutter to open. No data obtained on any systole on which a record was secured have been omitted.

The data given in the tables need explanation on only a few points. The padding number increases as more padding was placed on the mallet, and its exact meaning has been described (1). The vertical amplitudes of the ballistocardiogram

TABLE II

Data from experiments on $H . Z$.

\begin{tabular}{|c|c|c|c|c|c|c|c|c|c|c|c|c|c|c|c|}
\hline \multirow{3}{*}{$\begin{array}{c}\text { Curve } \\
\text { no. }\end{array}$} & \multirow{3}{*}{$\begin{array}{c}\text { Systolic } \\
\text { blow }\end{array}$} & \multirow{3}{*}{$\begin{array}{l}\text { Padding } \\
\text { number }\end{array}$} & \multirow{2}{*}{\multicolumn{2}{|c|}{ Aortic B.P. }} & \multirow{2}{*}{\multicolumn{2}{|c|}{ Femoral B.P. }} & \multirow{3}{*}{$\begin{array}{l}\text { Stroke } \\
\text { volume }\end{array}$} & \multirow{3}{*}{$\begin{array}{l}\text { Duration } \\
\text { of eject. }\end{array}$} & \multirow{3}{*}{$\begin{array}{l}\text { Pulse } \\
\text { wave } \\
\text { velocity }\end{array}$} & \multicolumn{6}{|c|}{ Ballistocardiograms } \\
\hline & & & & & & & & & & \multicolumn{2}{|c|}{ I Wave } & \multicolumn{2}{|c|}{ J Wave } & \multicolumn{2}{|c|}{ K Wave } \\
\hline & & & Syst. & Dias. & Syst. & Dias. & & & & Size & Dur. & Size & Dur. & Size & Dur. \\
\hline $\begin{array}{r}1 \\
2 \\
3 \\
4 \\
5 \\
6 \\
7 \\
8 \\
9 \\
10 \\
11 \\
13\end{array}$ & $\begin{array}{c}\text { ergs } \times 10^{-6} \\
14.8 \\
14.8 \\
14.8 \\
14.8 \\
32.8 \\
32.8 \\
14.8 \\
14.8 \\
14.8 \\
32.8 \\
5.2 \\
7.8\end{array}$ & $\begin{array}{l}2 \\
2 \\
3 \\
3 \\
3 \\
3 \\
2 \\
2 \\
2 \\
2 \\
2 \\
2\end{array}$ & $\begin{array}{c}m m . H g \\
134 \\
139 \\
141 \\
128 \\
196 \\
168 \\
78 \\
168 \\
123 \\
193 \\
91 \\
128\end{array}$ & $\begin{array}{c}m m . H g \\
68 \\
63 \\
76 \\
62 \\
76 \\
67 \\
36 \\
90 \\
62 \\
71 \\
64 \\
89\end{array}$ & $\begin{array}{c}m m . \mathrm{Hg} \\
133 \\
139 \\
150 \\
133 \\
193 \\
190 \\
88 \\
173 \\
138 \\
198 \\
95 \\
138\end{array}$ & $\begin{array}{c}m m . H g \\
64 \\
59 \\
72 \\
63 \\
78 \\
69 \\
40 \\
89 \\
65 \\
74 \\
70 \\
93\end{array}$ & $\begin{array}{l}c c . \\
48 \\
56 \\
44 \\
47 \\
67 \\
69 \\
63 \\
42 \\
51 \\
68 \\
20 \\
20\end{array}$ & $\begin{array}{l}\text { sec. } \\
0.36 \\
0.36 \\
0.25 \\
0.34 \\
0.35 \\
0.34 \\
0.42 \\
0.20 \\
0.32 \\
0.26 \\
0.24 \\
0.18\end{array}$ & $\begin{array}{c}\text { m. per sec. } \\
8.9 \\
10.6 \\
11.1 \\
11.1 \\
10.6 \\
11.1 \\
6.1 \\
11.5 \\
11.1 \\
10.6 \\
10 \\
12.8\end{array}$ & $\begin{array}{c}m m . \\
3.8 \\
4.2 \\
2.9 \\
2.6 \\
4.2 \\
5.6 \\
7.7 \\
4.2 \\
2.2 \\
3.1 \\
0 \\
0\end{array}$ & $\begin{array}{l}\text { sec. } \\
0.062 \\
0.064 \\
0.064 \\
0.064 \\
0.06 \\
0.064 \\
0.082 \\
0.06 \\
0.05 \\
0.04\end{array}$ & $\begin{array}{r}m m . \\
9.2 \\
12.5 \\
9.8 \\
8.7 \\
15.0 \\
16.1 \\
18.5 \\
13.4 \\
10.4 \\
16.1 \\
1.5 \\
3.4\end{array}$ & $\begin{array}{l}\text { sec. } \\
0.10 \\
0.09 \\
0.086 \\
0.10 \\
0.096 \\
0.088 \\
0.082 \\
0.09 \\
0.10 \\
0.10 \\
0.12 \\
0.12\end{array}$ & $\begin{array}{c}m m . \\
2.3 \\
4.2 \\
3.3 \\
3.5 \\
5.4 \\
7.3 \\
14.6 \\
8.4 \\
4.4 \\
0 \\
0 \\
0.9\end{array}$ & $\begin{array}{l}\text { sec. } \\
0.09 \\
0.08 \\
0.08 \\
0.08 \\
0.08 \\
0.08 \\
0.072 \\
0.08 \\
0.10 \\
\\
\\
0.06\end{array}$ \\
\hline
\end{tabular}


TABLE III

Data from experiments on $R$. $R$.

\begin{tabular}{|c|c|c|c|c|c|c|c|c|c|c|c|c|c|c|c|}
\hline \multirow{3}{*}{$\begin{array}{c}\text { Curve } \\
\text { no. }\end{array}$} & \multirow{3}{*}{$\begin{array}{c}\text { Systolic } \\
\text { blow }\end{array}$} & \multirow{3}{*}{$\begin{array}{l}\text { Padding } \\
\text { number }\end{array}$} & \multirow{2}{*}{\multicolumn{2}{|c|}{ Aortic B.P. }} & \multirow{2}{*}{\multicolumn{2}{|c|}{ Femoral B.P. }} & \multirow{3}{*}{$\begin{array}{l}\text { Stroke } \\
\text { volume }\end{array}$} & \multirow{3}{*}{$\begin{array}{l}\text { Duration } \\
\text { of eject. }\end{array}$} & \multirow{3}{*}{$\begin{array}{l}\text { Pulse } \\
\text { wave } \\
\text { velocity }\end{array}$} & \multicolumn{6}{|c|}{ Ballistocardiograms } \\
\hline & & & & & & & & & & \multicolumn{2}{|c|}{ I Wave } & \multicolumn{2}{|c|}{ J Wave } & \multicolumn{2}{|c|}{ K Wave } \\
\hline & & & Syst. & Dias. & Syst. & Dias. & & & & Size & Dur. & Size & Dur. & Size & Dur. \\
\hline $\begin{array}{r}1 \\
2 \\
3 \\
4 \\
5 \\
6 \\
7 \\
8 \\
9 \\
10 \\
11 \\
12 \\
13 \\
14 \\
15\end{array}$ & $\begin{array}{c}\text { ergs } \times 10^{-6} \\
14.8 \\
14.8 \\
14.8 \\
14.8 \\
32.8 \\
32.8 \\
32.8 \\
32.8 \\
32.8 \\
32.8 \\
11.7 \\
11.7 \\
11.7 \\
14.8 \\
14.8\end{array}$ & $\begin{array}{l}2 \\
2 \\
2 \\
2 \\
2 \\
2 \\
2 \\
3 \\
3 \\
3 \\
3 \\
3 \\
3 \\
2 \\
2\end{array}$ & \begin{tabular}{|c|}
$m m . H g$ \\
114 \\
95 \\
68 \\
116 \\
146 \\
89 \\
149 \\
145 \\
65 \\
169 \\
114 \\
95 \\
54 \\
111 \\
119
\end{tabular} & \begin{tabular}{|c|}
$m m . H g$ \\
72 \\
54 \\
38 \\
68 \\
72 \\
27 \\
64 \\
61 \\
31 \\
77 \\
81 \\
64 \\
34 \\
65 \\
75
\end{tabular} & $\begin{array}{c}m m . H g \\
125 \\
109 \\
73 \\
121 \\
155 \\
62 \\
127 \\
145 \\
69 \\
174 \\
116 \\
103 \\
52 \\
110 \\
115\end{array}$ & \begin{tabular}{|c|}
$m m . H$ \\
74 \\
85 \\
36 \\
66 \\
69 \\
16 \\
43 \\
66 \\
30 \\
78 \\
79 \\
65 \\
33 \\
64 \\
65
\end{tabular} & $\begin{array}{l}c c . \\
36 \\
38 \\
43 \\
36 \\
46 \\
69 \\
54 \\
58 \\
69 \\
50 \\
23 \\
29 \\
41 \\
30 \\
36\end{array}$ & $\begin{array}{l}\text { sec. } \\
0.29 \\
0.28 \\
0.32 \\
0.26 \\
0.22 \\
0.30 \\
0.26 \\
0.31 \\
0.30 \\
0.26 \\
0.30 \\
0.27 \\
0.45 \\
0.20 \\
0.16\end{array}$ & $\begin{array}{c}\text { m. per sec. } \\
7.0 \\
5.7 \\
5.3 \\
6.2 \\
9.1 \\
4.2 \\
7.0 \\
6.0 \\
3.3 \\
7.0 \\
7.0 \\
6.6 \\
3.8 \\
7.0 \\
7.5\end{array}$ & \begin{tabular}{|r}
$m m$. \\
5.1 \\
6.1 \\
4.6 \\
5.6 \\
13 \\
14.9 \\
12.2 \\
4.9 \\
17.5 \\
5.8 \\
1.6 \\
1.7 \\
3.3 \\
3.3 \\
5.9
\end{tabular} & $\begin{array}{l}\text { sec. } \\
0.07 \\
0.09 \\
0.09 \\
0.08 \\
0.08 \\
0.09 \\
0.08 \\
0.08 \\
0.13 \\
0.08 \\
0.07 \\
0.10 \\
0.09 \\
0.08 \\
0.07\end{array}$ & $\begin{array}{r}m m . \\
7.3 \\
12.5 \\
9.1 \\
10.6 \\
25.4 \\
35.8 \\
23.9 \\
11.9 \\
15.5 \\
14.2 \\
3.7 \\
4.5 \\
6.1 \\
7.2 \\
12.3\end{array}$ & \begin{tabular}{|l} 
sec. \\
0.10 \\
0.09 \\
0.11 \\
0.09 \\
0.08 \\
0.10 \\
0.08 \\
0.10 \\
0.09 \\
0.08 \\
0.09 \\
0.09 \\
0.11 \\
0.10 \\
0.10
\end{tabular} & $\begin{array}{r}m m . \\
5.1 \\
11.0 \\
4.6 \\
6.7 \\
21.6 \\
26.8 \\
23.3 \\
8.1 \\
10.5 \\
11.6 \\
2.1 \\
1.7 \\
1.7 \\
6.7 \\
5.0\end{array}$ & $\begin{array}{l}\text { sec. } \\
0.08 \\
0.07 \\
0.06 \\
0.07 \\
0.06 \\
0.06 \\
0.06 \\
0.06 \\
0.07 \\
0.06 \\
0.10 \\
0.07 \\
0.06 \\
0.07 \\
0.06\end{array}$ \\
\hline
\end{tabular}

waves were measured from the records' base line.

The systolic ejection curves given in Figure 4 are numbered to correspond with the curve number in the tables, as are the points in Figures 5 , 6 and 7.

\section{ANALYSIS OF RESULTS}

We will present our analysis of the results in much the same order as our ideas developed.

We started this study by plotting the sum of the vertical depth of the I wave and the vertical height of the $\mathrm{J}$ wave, to be called the $\mathrm{I}+\mathrm{J}$ distance, against the cardiac output as the results of each experiment came in; typical plots for four subjects are given in Figure 5. Inspection of these figures show at once that the correlation is remarkably good for the M. L. data, where the regression is evidently curved, but the scatter is greater in the data secured on H. Z. and R. R., and is much greater for that of $M$. M. Inspection of the data secured on the last three subjects shows that the greater scatter is largely due to results obtained in systoles in which the mallet padding was increased (results represented by underlined dots in Figure 5), these values tending to gather to the right and below the other data. Indeed, in

TABLE IV

Data from experiments on $J . W$.

\begin{tabular}{|c|c|c|c|c|c|c|c|c|c|c|c|c|c|c|c|}
\hline \multirow{3}{*}{$\begin{array}{c}\text { Curve } \\
\text { no. }\end{array}$} & \multirow{3}{*}{$\begin{array}{c}\text { Systolic } \\
\text { blow }\end{array}$} & \multirow{3}{*}{$\begin{array}{l}\text { Padding } \\
\text { number }\end{array}$} & \multirow{2}{*}{\multicolumn{2}{|c|}{ Aortic B.P. }} & \multirow{2}{*}{\multicolumn{2}{|c|}{ Femoral B.P. }} & \multirow{3}{*}{$\begin{array}{l}\text { Stroke } \\
\text { volume }\end{array}$} & \multirow{3}{*}{$\begin{array}{l}\text { Duration } \\
\text { of eject. }\end{array}$} & \multirow{3}{*}{$\begin{array}{c}\text { Pulse } \\
\text { wave } \\
\text { velocity }\end{array}$} & \multicolumn{6}{|c|}{ Ballistocardiograms } \\
\hline & & & & & & & & & & \multicolumn{2}{|c|}{ I Wave } & \multicolumn{2}{|c|}{ J Wave } & \multicolumn{2}{|c|}{ K Wave } \\
\hline & & & Syst. & Dias. & Syst. & Dias. & & & & Size & Dur. & Size & Dur. & Size & Dur. \\
\hline $\begin{array}{r}2 \\
3 \\
5 \\
6 \\
7 \\
8 \\
9 \\
10 \\
11 \\
12 \\
14 \\
15\end{array}$ & $\begin{array}{c}\text { ergs } \times 10^{-6} \\
15.2 \\
11.0 \\
15.2 \\
15.2 \\
15.2 \\
15.2 \\
15.2 \\
\text { Hand } \\
\text { Hand } \\
14.2 \\
17.3 \\
17.3\end{array}$ & $\begin{array}{l}2 \\
2 \\
2 \\
2 \\
2 \\
2 \\
2 \\
2 \\
2 \\
2 \\
2 \\
2\end{array}$ & $\begin{array}{r}94 \\
115 \\
102 \\
56 \\
105 \\
88 \\
82 \\
117 \\
42\end{array}$ & $\begin{array}{l}52 \\
73 \\
60 \\
29 \\
77 \\
48 \\
45 \\
71 \\
29\end{array}$ & \begin{tabular}{|c|}
$m m . H g$ \\
102 \\
81 \\
90 \\
96 \\
111 \\
96 \\
67 \\
89 \\
86 \\
89 \\
105 \\
42
\end{tabular} & \begin{tabular}{|c|} 
mm. $\mathrm{Hg}$ \\
50 \\
53 \\
48 \\
51 \\
67 \\
52 \\
31 \\
59 \\
46 \\
48 \\
43 \\
29
\end{tabular} & $\begin{array}{l}c c . \\
43 \\
26 \\
36 \\
37 \\
32 \\
36 \\
48 \\
46 \\
55 \\
48 \\
51 \\
30\end{array}$ & $\begin{array}{l}\text { sec. } \\
0.32 \\
0.33 \\
0.34 \\
0.33 \\
0.25 \\
0.26 \\
0.39 \\
0.58 \\
0.65 \\
0.36 \\
0.35 \\
0.44\end{array}$ & $\begin{array}{l}5.8 \\
8.2 \\
6.6 \\
5.1 \\
5.1 \\
5.1 \\
6.0 \\
7.3 \\
5.1\end{array}$ & $\begin{array}{c}m m . \\
3.3 \\
2.5 \\
3.3 \\
3.3 \\
5.0 \\
3.3 \\
4.2 \\
0.4 \\
0 \\
3.3 \\
5.0 \\
1.7\end{array}$ & $\begin{array}{l}\text { sec. } \\
0.06 \\
0.06 \\
0.06 \\
0.07 \\
0.07 \\
0.06 \\
0.06 \\
0.04 \\
0 \\
0.06 \\
0.07 \\
0.07\end{array}$ & $\begin{array}{l}m m . \\
3.7 \\
2.5 \\
5.4 \\
7.5 \\
5.8 \\
7.5 \\
5.8 \\
3.3 \\
4.6 \\
5.0 \\
7.5 \\
2.5\end{array}$ & $\begin{array}{l}\text { sec. } \\
0.13 \\
0.09 \\
0.10 \\
0.07 \\
0.08 \\
0.08 \\
0.09 \\
0.09 \\
0.08 \\
0.12 \\
0.10 \\
0.13\end{array}$ & $\begin{array}{c}m m . \\
0 \\
2.8 \\
0 \\
2.0 \\
2.5 \\
2.0 \\
2.0 \\
2.6 \\
2.5 \\
1.5 \\
2.5 \\
2.0\end{array}$ & $\begin{array}{c}\text { sec. } \\
0 \\
0.06 \\
\\
0.04 \\
0.05 \\
0.04 \\
0.04 \\
0.05 \\
0.05 \\
0.03 \\
0.05 \\
0.04\end{array}$ \\
\hline
\end{tabular}


TABLE V

Data from experiments on $M . M$.

\begin{tabular}{|c|c|c|c|c|c|c|c|c|c|c|c|c|c|c|c|}
\hline \multirow{3}{*}{$\begin{array}{c}\text { Curve } \\
\text { no. }\end{array}$} & \multirow{3}{*}{$\begin{array}{c}\text { Systolic } \\
\text { blow }\end{array}$} & \multirow{3}{*}{$\begin{array}{l}\text { Padding } \\
\text { number }\end{array}$} & \multirow{2}{*}{\multicolumn{2}{|c|}{$\begin{array}{l}\text { Pul. art. or } \\
\text { aortic B.P. }\end{array}$}} & \multirow{2}{*}{\multicolumn{2}{|c|}{ Femoral B.P. }} & \multirow{3}{*}{$\begin{array}{l}\text { Stroke } \\
\text { volume }\end{array}$} & \multirow{3}{*}{$\begin{array}{l}\text { Duration } \\
\text { of eject. }\end{array}$} & \multirow{3}{*}{$\begin{array}{l}\text { Pulse } \\
\text { wave } \\
\text { velocity }\end{array}$} & \multicolumn{6}{|c|}{ Ballistocardiograms } \\
\hline & & & & & & & & & & \multicolumn{2}{|c|}{ I Wave } & \multicolumn{2}{|c|}{ J Wave } & \multicolumn{2}{|c|}{ K Wave } \\
\hline & & & Syst. & Dias. & Syst. & Dias. & & & & Size & Dur. & Size & Dur. & Size & Dur. \\
\hline $\begin{array}{l}2 \\
3 \\
4 \\
5 \\
6 \\
7 \\
8\end{array}$ & $\begin{array}{c}\text { ergs } \times 10^{-0} \\
7.8 \\
31.1 \\
19.2 \\
19.2 \\
19.2 \\
19.2 \\
19.2\end{array}$ & $\begin{array}{l}2 \\
2 \\
2 \\
4 \\
1 \\
2 \\
2\end{array}$ & $\begin{array}{c}\text { mm. } H g \\
46 \\
41 \\
68 \\
77 \\
81 \\
52 \\
103\end{array}$ & $\begin{array}{c}\mathrm{mm} . \mathrm{Hg} \\
1 \\
8 \\
49 \\
61 \\
66 \\
38 \\
80\end{array}$ & \begin{tabular}{|c|} 
mm. $\boldsymbol{H g}$ \\
94 \\
94 \\
80 \\
80 \\
83 \\
59 \\
115
\end{tabular} & \begin{tabular}{|c|}
$m m . H g$ \\
63 \\
49 \\
51 \\
61 \\
66 \\
36 \\
84
\end{tabular} & $\begin{array}{l}c c . \\
28 \\
54 \\
58 \\
68 \\
62 \\
60 \\
44\end{array}$ & $\begin{array}{l}\text { sec. } \\
0.28 \\
0.25 \\
0.36 \\
0.64 \\
0.32 \\
0.38 \\
0.28\end{array}$ & $\begin{array}{l}4.8 \\
4.6 \\
5.0 \\
3.4 \\
5.6\end{array}$ & $\begin{array}{c}m m . \\
0 \\
2.0 \\
1.6 \\
0.4 \\
4.8 \\
1.6 \\
2.9\end{array}$ & $\begin{array}{c}\text { sec. } \\
0 \\
0.06 \\
0.05 \\
0.08 \\
0.08 \\
0.05 \\
0.06\end{array}$ & $\begin{array}{r}m m . \\
2.8 \\
11.3 \\
7.3 \\
1.6 \\
11.3 \\
4.8 \\
5.6\end{array}$ & $\begin{array}{l}\text { sec. } \\
0.13 \\
0.10 \\
0.11 \\
0.11 \\
0.08 \\
0.10 \\
0.09\end{array}$ & $\begin{array}{r}m m . \\
0.4 \\
14.1 \\
8.1 \\
1.6 \\
8.9 \\
6.4 \\
5.6\end{array}$ & $\begin{array}{l}\text { sec. } \\
0.14 \\
0.11 \\
0.09 \\
0.28 \\
0.08 \\
0.10 \\
0.09\end{array}$ \\
\hline
\end{tabular}

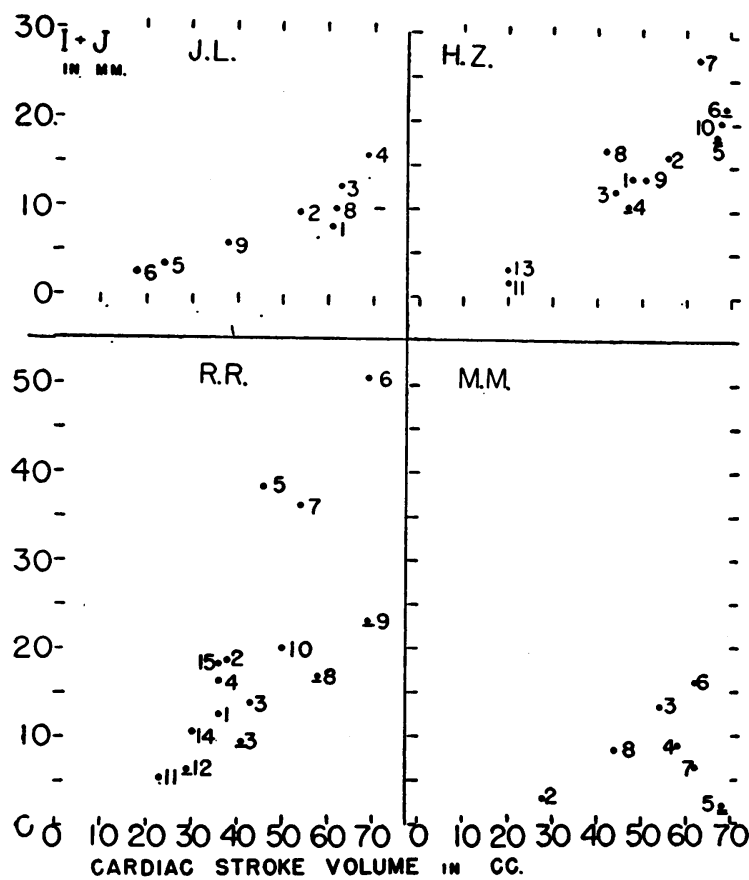

Fig. 5. Dot Diagrams Showing the Relation of the Ballistic Amplitude, as Measured by the Vertical I + J Distance, to the Systolic Stroke Volume in EXPERIMENTS on Four SUbJects

The data on any subject are to be identified by the initials. The numbers adjacent to the points correspond to the numbers given systoles in the tables and in the curves in Figure 4. In diagram at upper left J.L. should be M.L.

The results of certain experiments in which extra padding was added to the mallet can be identified by bars under the dots.

the data of $R$. R. inspection suggests that there is one regression for the harder and another for the softer blows. Obviously, the reason for the better agreement in the case of M. L. is that the same mallet padding was used throughout this experiment. One therefore must conclude that the size of the $\mathrm{I}+\mathrm{J}$ distance would measure the cardiac output well, only in the absence of such changes in cardiac function as are simulated by increasing the mallet's padding. That variations in cardiac function causing a change in the form of the cardiac ejection curve would alter the relation between the amplitude of the record and the cardiac output was realized in our first communication on this subject (5), and a further study of the important relationship between the ballistocardiogram and cardiac output will be the subject of another paper.

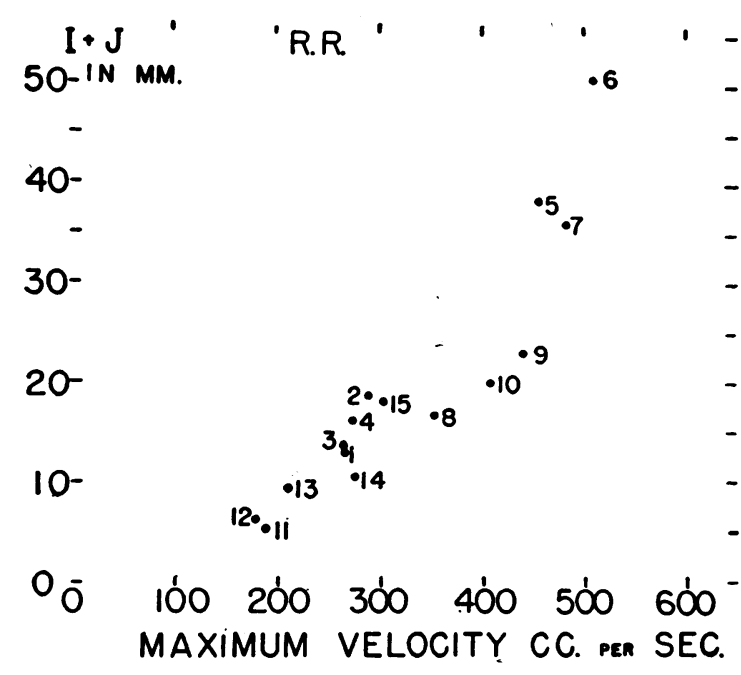

Fig. 6. Dot Diagram Showing the Relation of Ballistic Amplitude to the Maximum Velocity of Cardiac Ejection

The numbers next to the dots correspond with the numbers of systoles in Table III. Data from subject $\mathbf{R}$. $\mathbf{R}$. 


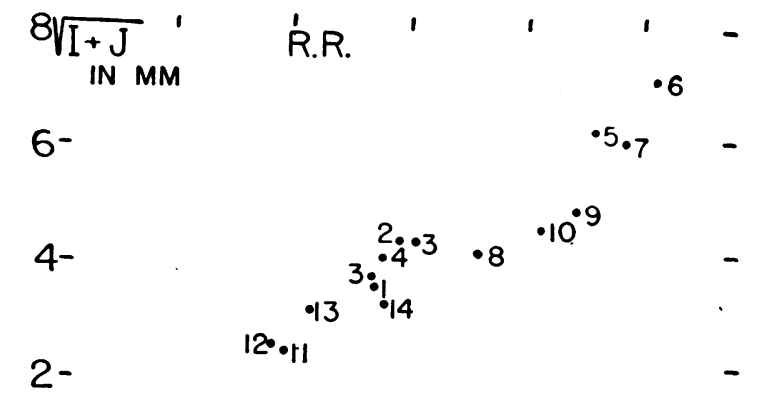

 MAXIMUM VELOCITY CC PER SEC}

Fig. 7. Dot Diagram Showing Relation of the Square Root of Ballistic Amplitude to the Maximum Velocity of Cardiac Ejection

The numbers are as before. Data from subject $\mathbf{R}$. $\mathbf{R}$.

Comparing the vertical $\mathrm{J}+\mathrm{K}$ distance with cardiac output leads to still greater scatter and we have not reproduced the dot diagrams. Obviously the size of the cardiac output, considered by itself, is not the prime factor in determining the ballistocardiogram's amplitude.

As the data on M. L. appear to conform to a curve convex upward the next step is obviously to try the effect of plotting the square root of the $\mathrm{I}+\mathrm{J}$ values against the stroke volume. This change diminishes the scatter in some subjects and the regression more nearly passes through the zero point, but it does not meet the need of pulling into line the results secured after the softer systolic blows.

Plotting the $\mathrm{I}+\mathrm{J}$ amplitude, or $\sqrt{\mathrm{I}+\mathrm{J}}$, against the left ventricular work or power, both calculated for us dynamically from the stroke volume and aortic pressure curves by Mr. Walter Feder, likewise does not lead to improvement in the scatter, and the value secured after the systoles made with heavier padding are still outlying to the right and downward. The relation of our results to such estimates of work or power will be studied further so these dot diagrams will not be reproduced here.

The plan of comparing the ballistic amplitude directly with the more familiar aspects of cardiac function not having yielded a close correlation, we turned to analysis of the cardiac output curves given in Figure 4 and soon had a clue. When the force of the blow is diminished by dropping the mallet through a smaller arc both the stroke volume and the slope of the cardiac ejection curve are diminished; the curves given in Figure 4 show many examples of this. In a few instances, however, pairs of experiments can be found in which the cardiac output is the same in each, but the slope of the ejection curve differs. Thus if one looks carefully at the curves No. 7 and 8 on R. R. in Figure 4 , and then inspects the corresponding dots in Figure 5, one sees that the cardiac output is nearly the same in both, but the ejection curve of No. 7 rises faster than that of No. 8. The same can be said of curves 9 and 6 of R. R. and for other pairs of curves in other subjects, although the difference between the slopes is seen with much more difficulty in the reduced Figure 4 than in the original records. In these pairs the steeper curve is always accompanied by a ballistocardiogram of greater amplitude, so we are led to inspect the relation between the square root of the amplitude of the $\mathrm{I}+\mathrm{J}$ waves and the slope of the ejection curve at the steepest point. A plot of $I+J$, or $\sqrt{I+J}$, against the maximum slope of the curve measured as the angle from the horizontal in degrees showed too much scatter to be promising, but it was soon apparent that what was needed was not the angle itself but its tangent, which measures the maximum velocity attained during the ejection.

In Figure 6 the slopes of the curves of R. R., estimated from the tangent of the angle made by the steepest part of the curve with the horizontal, corrected by the calibration of the vertical limb in cc. and the horizontal limb for time, are plotted against the $\mathrm{I}+\mathrm{J}$ distance. Comparison with Figure 5 shows that the improvement in scatter is remarkable. The regression is now plainly curved by using $\sqrt{\mathrm{I}+\mathrm{J}}$ instead of $\mathrm{I}+\mathrm{J}$ and we get the much straighter alignment shown in Figure 7. Obviously, we are now on a promising line of attack.

The plot of $\sqrt{\mathrm{I}+\mathrm{J}}$ against maximal velocity for all five subjects is shown in Figure 8. Inspection shows that the correlation now is of a high order, $\tau=0.82$, and one is certainly tempted to stop here. Nevertheless, further inspection shows that the data of the heaviest subject, M. M., tends to outlie to the right and downward, while that of the lightest subject, J. W., tends to outlie to the left and upward, a finding which plainly suggests 


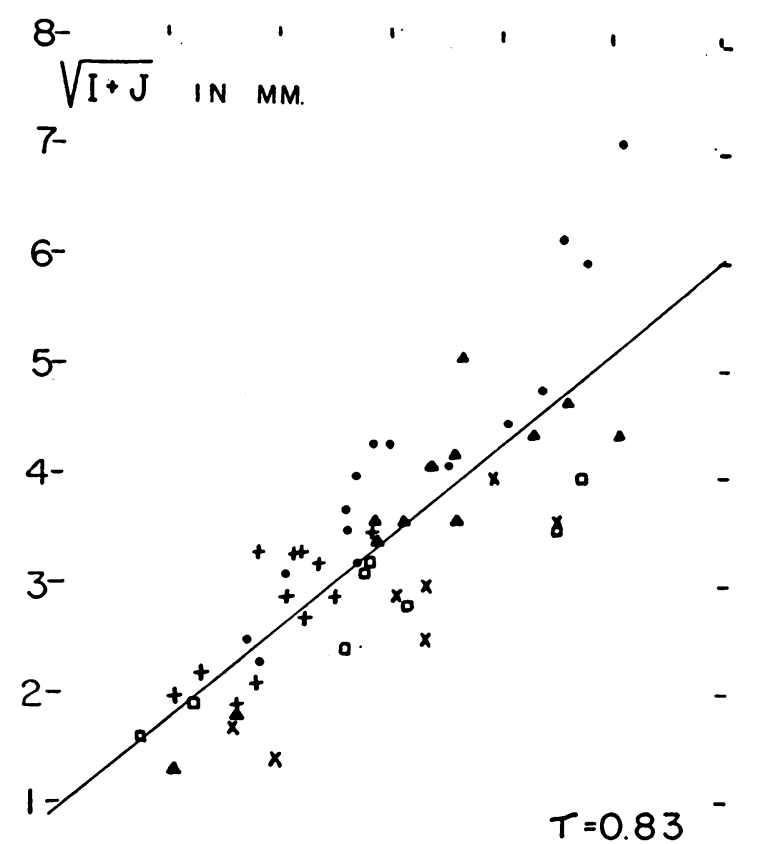

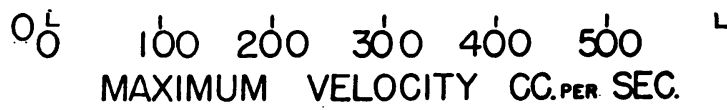

Fig. 8. Dot Diagrams Showing the Relation beTWEen $\sqrt{\mathrm{I}+\mathrm{J}}$ and MAXIMUM Velocity OF EJection for All Five Subjects

Dots $=$ R. R. ; triangles $=$ H. Z. ; squares $=$ M. L. ; crosses $=\mathrm{J}$. W.; $\mathrm{x}^{\prime} \mathrm{s}=\mathrm{M}$. M. The line is the calculated regression $\boldsymbol{x}$ on $\boldsymbol{y}$.

that a consideration of the subject's size would further diminish the scatter.

So our next step was to plot the $\sqrt{I+J}$ against the maximal velocity of the ejection curve divided by the surface area for each subject, with the result shown in Figure 9; the correlation is now surprisingly good, $\tau=0.92$ a value which, when tested by Fisher's $Z$ function (4), proves to be significantly better than the correlation secured without considering the subject's size.

We studied the data further by measuring the time from the beginning of ejection to the point at which maximum velocity was reached. In most curves it was difficult to determine this point exactly and the two authors reading independently often differed considerably in their measurements. We made a dot diagram to compare the $\sqrt{\mathrm{I}+\mathrm{J}}$ with maximum velocity $\div$ the time required to attain it, the quotient being average acceleration. The correlation was very evident but inspection showed that it was clearly not so good as that shown in Figures 8 and 9. The error in measuring the time required to attain maximum velocity was undoubtedly a large factor in the scatter and so we were discouraged from pursuing the matter further.

\section{DISCUSSION}

It seems proper to expect that such aspects of cardiac function as output, work, energy, force, and power will vary together throughout a wide range of physiological and clinical conditions, so it should occasion no surprise if the ballistic amplitude was found to be significantly correlated with more than one of them. But the wide range of our experimental conditions permits distinctions which would be difficult or impossible to draw from data secured during life.

The maximum velocity of our ejection curves is so closely correlated to the amplitude of the

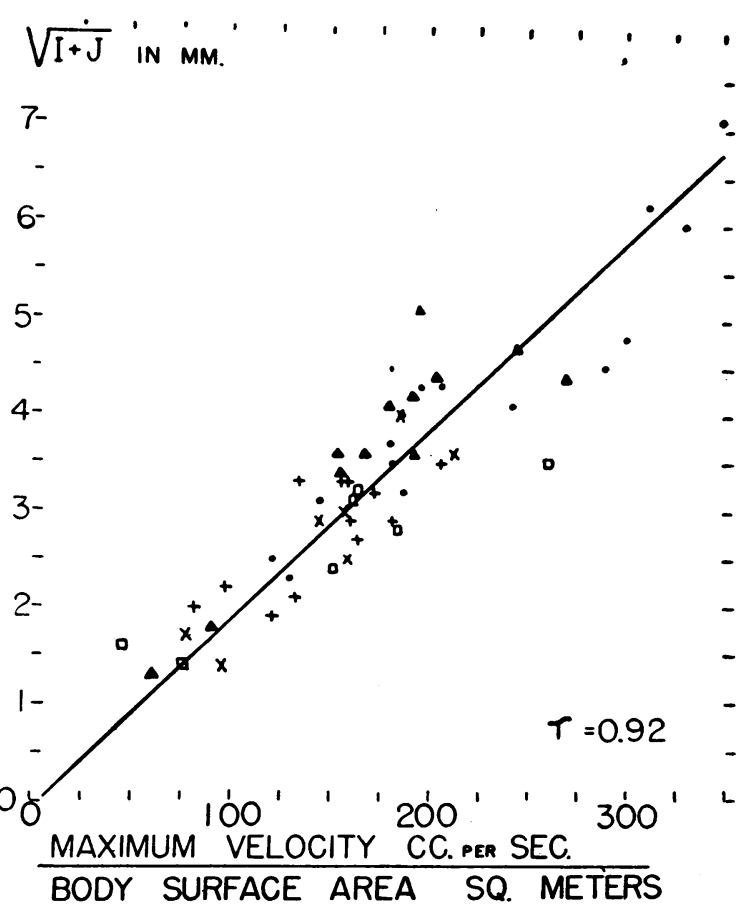

Fig. 9. Dot Diagram Showing the Relation between $\sqrt{\mathrm{I}+\mathrm{J}}$ and Maximum Velocity of Ejection Divided by Body Surface Area

Symbols as in Figure 8. The best line is the calculated regression $x$ on $y$, this regression being used because we propose to employ its equation in estimating maximum velocity of ejection from $\sqrt{\mathrm{I}+\mathrm{J}}$, that is from the amplitude of the ballistocardiogram in any record. 
ballistocardiogram that the known errors of reading the record may in large measure account for the scatter we find, and this relation holds so well throughout such a great diversity of experimental conditions that one has the right to expect it will hold for most of the common clinical conditions.

We believe that the maximum velocity shown by our curves gives us an indication of the force of the heart beat for the following reasons. By definition this force is estimated from the product of mass times acceleration, and the maximum velocity of our curves is the integral of the accelerations of which it is the result.

The maximum velocity recorded by our curves is in units of cubic centimeters per second; since the specific gravity of blood is close to one, the values for grams per second would be very similar. By consideration of the size of the aortic cannula or of the aorta itself, linear velocity could be readily computed, but when linear velocity varies with changes in the diameter of the conducting tubes the mass of the contained blood varies inversely, so the product of mass $\times$ veolcity, or of mass $\times$ acceleration, is independent of the vessel diameter (6).

Thus the amplitude of the ballistocardiogram seems to be plainly related to cardiac force, but we are not yet in position to estimate cardiac force in absolute units because of the uncertainty about the mass of the blood caused to move in the body by the heart's energy at any instant of time. a mass that certainly far exceeds the stroke volume itself because blood is pushed on ahead of that ejected by the heart. This difficulty has been discussed (2), and we propose to content ourselves with relative estimations of cardiac force until our ideas of the energetics of cardiac action are clearer then they are at present, and because of increasing doubts that the classic methods of estimating cardiac work provide the best approach to the problem.

The arrangement of our data reported in the preceding paper (1) showed that the amplitude of the ballistocardiogram is related to the total energy delivered to the circulation during systole only if that energy is supplied in a constant manner. Energy delivered rapidly produced a far larger ballistocardiogram than the same energy delivered slowly, so it appeared to be energy per unit of time which was the genesis of the ballistic deflections (1). The relationship of this conception to the data described in this paper is easy to see. In our experiments, when provided with little padding the falling mallet was stopped rapidly as it struck the syringe pistons, and the blood was accelerated rapidly by the energy thus rapidly delivered; when provided with much padding the falling mallet was stopped much more slowly and the blood was accelerated more slowly. So the relationship between our results and the force delivered to the circulation is plain. The interpretation described in this paper does much to clarify the ideas expressed more crudely before.

This new evidence that the amplitude of the ballistocardiogram is a measure of cardiac force comes as no surprise to us. The equation for force according to Newton's Laws was the basic equation from which our original treatment of the mathematical theory was derived (5); also, in our first experiments on the cadaver the data led to a similar conclusion; indeed, although the former method of measuring acceleration from our curves (2) was cruder than that described in this publication, the correlation coefficients relating ballistic amplitude to acceleration are almost identical in the two groups of data (2), and the improvement in the correlation in our recent work is manifest only by the fact that, dealing with larger numbers of estimates in this paper, the level required for significance is lower.

In our first study (2), the data did not permit a decision whether $\mathrm{I}+\mathrm{J}$ or $\sqrt{\mathrm{I}+\mathrm{J}}$ permitted a better estimate of cardiac performance. The newer data permit this decision; $\sqrt{\mathrm{I}+\mathrm{J}}$ is significantly better. Interestingly enough this was predicted from theory (5). We have also asked ourselves the question whether data based on the areas of the $I$ and $J$ waves, treated as triangles with their bases on the record's base line, would permit a better estimation of cardiac force than using the sum of the vertical depth of $I$ and height of $J$. The equations given in Table VI show that the scatter about the two regressions is almost identical, but our early experience with dynamic calibration of ballistocardiographs (5) provides a strong reason for basing estimates on areas, because secondary vibrations may greatly affect the height of a wave's 
TABLE VI

Regression equations-maximum velocity as a relative measure of cardiac force as derived from measurements of the ballistocardiogram and the body surface area*

\begin{tabular}{|c|c|c|}
\hline $\begin{array}{l}\text { Equation } \\
\text { no. }\end{array}$ & & $\sigma_{\mathbf{x y}}$ \\
\hline 1 & Maximum velocity $c c$. per sec. $=75.8 \sqrt{\mathrm{I}+\mathrm{J} \text { amplitude } m m .}+37$ & $55.5 c c$. per sec. \\
\hline 2 & Max. vel. $c c$. per sec. $=[$ body surface $s q . m].[51 \sqrt{\mathrm{I}+\mathrm{J} \text { amplitude } m m .}+5]$ & $28 c c$. per sec. \\
\hline 3 & Max. vel. $c c$. per sec. $=[$ body surface sq. m. $][252 \sqrt{\mathrm{I}+\mathrm{J} \text { areas } m m . \text { sec. }}-5]$ & $29 c c$. per sec. \\
\hline
\end{tabular}

* Vertical amplitudes of the ballistic waves measured in millimeters from the base line may be used in these equations only if the calibration of the ballistocardiogram is standard, i.e., a force of 280 grams produces a deflection of $10 \mathrm{~mm}$. on the record. If the calibration is not standard the measurements on the records must be corrected to this value before inserting them in these equations.

tip when they have little or no effect on the area of the wave.

While the clear relation of the ballistic amplitude to cardiac force indicated in our newer results was in accord with our expectations $(1,2)$, the advantage of multiplying the measurements made on the record by a factor related to body size came to us as a surprise. In our previous study (2) the three subjects whose data provided the comparison between acceleration and ballistic size had been of almost identical height and two were of identical weight. So the effect of size on the relationship was not apparent on inspection of the dot diagrams and the effect of the introduction of a size factor was not investigated.

Other aspects of our recent work have given indications of impedance in our system, and it seems proper to locate this in the body rather than in the apparatus. Our ballistocardiograph is so sensitive and so little damped that, in the absence of a body upon it, the vibrations in the building keep it in motion continuously, so it seems evident that no noteworthy impedance occurs in it. Place a body upon it and the light spot comes to rest, as can be seen by the straight base lines of our records. As the calibrations shown in Figure 2 indicate, the damping in the body is often close to critical when forces corresponding in magnitude to those which produce the ballistocardiograms are used to test it ; but in certain other cadavers, similar tests indicate that the body's damping may also be somewhat less than critical. Obviously we have every right to locate the impedance in the body, and this provides a satisfactory explanation of other findings.

Thus, in the usual systole illustrated by the great majority of curves shown in Figure 4, the first ballistic deflection, the onset of the downstroke of the I wave, follows the beginning of ejection by an interval so short that it is hardly measurable; this is illustrated by the first three of the curves shown in Figure 2. But if the injection is initiated more slowly as in curves 10 and 11 in $\mathrm{J}$. W. and in curve 13 in H. Z. in Figure 4, no deflection follows the onset of ejection for a much longer time; and, as can be seen in the last curve in Figure 2, the first deflection may then be headward. Indeed, in early experiments in which water was used as perfusing fluid, we were able to inject amounts over $50 \mathrm{cc}$. into each of the great vessels, by pushing in the syringes slowly by hand, without causing any ballistic deflection whatsoever, although certainly some force was being generated. Obviously therefore, small amounts of force generated deep in the body are so impeded that they do not "get through" to produce a deflection of the ballistocardiogram; and when the force generated is of a certain small magnitude, that which tends to cause the I wave may be blocked while the larger forces causing the $J$ wave break through to produce a small deflection as is seen in the last curve of Figure 2. Thus by an injection which accelerates slowly we can reproduce complexes lacking an I wave which are similar to those found so frequently in records taken in the clinic, and we have a satisfactory explanation for this common abnormality of contour.

That increased fat would impede the delivery of the heart's energy to the ballistocardiogram was suspected by Bouhuys (7), and looking backward over older data from this laboratory, one sees that we have had other hints of the need of introducing a factor related to body size into our 
basic equations. Indeed there was such a factor, "A", an estimate of aortic cross section area from the surface area and age of the patient, in our original cardiac output equation (5). Looked upon from the vantage point of 15 years experience, we see that " $A$ " not only supplied the need for a factor related to body size, but also, because it increased with age, it provided a compensation for the diminishing size of the ballistocardiogram as age advances (8), and both aspects served to reduce the scatter of the normal standards. When we omitted " $A$ " from our equation, for mathematical reasons which still seem valid (6), the scatter of the results secured on normal subjects increased considerably.

This newly demonstrated influence of body size throws light on a puzzling finding discovered in the data of other clinics besides this one (9-11). It has always been obvious by inspection that, on the average, men give larger ballistocardiograms than women, and women larger than children; so the concept that the amplitude of the ballistocardiogram is related to body size seems obviously correct. Indeed, if data from healthy men and women are combined in a single group, significant positive correlation between amplitude of ballistocardiogram and body surface area is readily demonstrated. But it came as a surprise to discover that in groups consisting of healthy adult males only, or of healthy women only, the correlation between ballistic amplitude and body surface was no longer significant. The reason now seems obvious. It is proper to regard the force of the resting heart beat as correlated with body size, but this relation is in part masked by the increased impedance of the larger bodies, so that one needs a large number of cases and a wide spread of the data before the correlation between ballistic amplitude and body size can be conclusively demonstrated.

Our results also throw light on one of the chief uncertainties of the field which may be called the errors in transmission. Even if ballistocardiographs could be made mechanically perfect, one could not avoid the hazard involved in attempting to record forces generated in the center of the body by apparatus placed outside it (12). Various parts of the body must be thought of as masses of tissue elastically connected one with another, and completely firm attachment of the elastic body to the rigid ballistocardiograph is obviously impossible to secure (13). These factors introduce distortion into the record, and so, as we have always emphasized, the ballistocardiogram cannot be expected to give a completely true account of the forces generated deep in the body of which it is a manifestation $(5,12,14)$. While some data on the movement between the body and the table has been secured (7), and this subject deserves further study, the errors inherent in the transmission of forces along the mechanical train within the body have been more difficult to evaluate. The problem is not whether there is distortion, which we freely concede is to be expected, but whether the distortion is sufficiently uniform from time to time and from subject to subject to permit one to avoid the error of interpreting as changes in cardiac function, changes in the ballistocardiogram due in reality to differences in the body tissues, or in the attachment of the subject to the ballistocardiograph.

Evidence available for some years has clearly suggested that as far as the $I$ and $J$ waves are concerned, any distortion introduced by the errors of transmission behaves in an orderly way. The extraordinary similarity of contour of ballistocardiograms secured in healthy young adults of great diversity of size and body build, recorded by ballistocardiographs completely different in form and construction, can hardly be interpreted otherwise. But such data, impressive though they are, do not give quantitative information on the point.

In the experiments described in this paper, the ballistocardiograms secured are subject to all the errors of transmission which occur in similar records obtained during life, for we are recording forces generated deep in the body, indeed, generated at the same places and in the same manner as occurs during life, by apparatus placed outside the body; and the attachment of our cadavers to the ballistic table, as they lay on it with their heels firmly against the footplate, is identical with the technique we use when taking records during life.

We interpret the demonstration that the size of the body affects our results as providing the first important information about the errors of transmission. But, after correction for body size has been made, the correlation between our rela- 
tive estimate of cardiac force and the amplitude of the ballistic record becomes so good that it seems evident that the other irregularities in the transmission of the forces affect little, if at all, our ability to form a quantitative estimate of the relative strength of the heart's beating by measuring the amplitude of the ballistocardiogram; and, in our data, the error of the estimate compares well with that of other useful clinical measurements such as the estimation of the blood pressure (2).

\section{SUMMARY}

The results of experiments are reported in which cardiac systole was simulated at necropsy by simultaneous and similar injections of blood into the aorta and pulmonary artery, after a systemic diastolic pressure had been secured by an infusion of blood into the femoral artery. These experiments were conducted under widely different conditions of stroke volume and blood pressure, and both in arteriosclerotic subjects and in those with normal vessels.

The amplitude of the resulting ballistocardiograms, determined by the vertical distance between I and J wave tips, or by the sum of the areas of the $I$ and J waves, correlated well with the "cardiac outputs" in certain types of experiments, but under other conditions the relation changed. Similarly the relation between the ballistic amplitude and "cardiac" work or power did not hold well throughout the varying conditions existing in the experiments.

However, a study of the curves of systolic ejection of blood at each instant of time indicated that the square root of the amplitude of the ballistocardiogram, $\sqrt{\mathrm{I}+\mathrm{J}}$, correlated well with the maximum velocity of ejection throughout the range of our experiments; and this relation was significantly bettered by the inclusion of the body surface area as a factor in the equation, so that the final correlation was most gratifying.

As the maximum velocity of the injected blood is equal to the integral of the acceleration which preceded it, it is concluded that the amplitude of the ballistocardiogram is related to the force of the heart, and that this relation holds well over a wide range of clinical conditions. However, the larger the subject's body, the greater the impedance to the delivery of the heart's force to the ballistocardiograph, so that a correction for body size improves the estimate of the heart's force from measurements made on the ballistocardiogram.

While uncertainties about the fundamental dynamics of cardiac action prevent an estimation of cardiac force in absolute units, it seems entirely proper to employ the ballistocardiogram to estimate cardiac force in relative terms, and thus compare the strength of the heart's contraction in normal and abnormal persons, and under many different physiological and clinical conditions.

\section{REFERENCES}

1. Starr, I., Schnabel, T. G., Jr., and Mayock, R. L., Studies made by simulating systole at necropsy. II. Experiments in the relation of cardiac and peripheral factors to the genesis of the pulse wave and the ballistocardiogram. Circulation, 1953, 8, 44.

2. Starr, I., Horwitz, O., Mayock, R. L., and Krumbhaar, E. B., Standardization of the ballistocardiogram by simulation of the heart's function at necropsy; with a clinical method for the estimation of cardiac strength and normal standards for it. Circulation, 1950, 1, 1073.

3. Lilly, J. C., Legallais, V., and Cherry, R., A variable capacitor for measurements of pressure and mechanical displacements; a theoretical analysis and its experimental evaluations. J. Applied Physics, 1947, 18, 613.

4. Snedecor, G. W., Statistical Methods Applied to Experiments in Agriculture and Biology, ed. 4, Ames, Iowa, Iowa State College Press, 1946, p. 485.

5. Starr, I., Rawson, A. J., Schroeder, H. A., and Joseph, N. R., Studies on the estimation of cardiac output in man, and of abnormalities in cardiac function, from the heart's recoil and the blood's impacts; the ballistocardiogram. Am. J. Physiol., 1939, 127, 1.

6. Starr, I., A theoretical study on the effect of aortic size on the ballistocardiogram. Federation Proc., 1944, 3, 45.

7. Bouhuys, A., High frequency ballistocardiography. I. Proceedings, Koninkl. Nederl. Akademie van Wetenschappen-Amsterdam, series C, 1952, 55, 126.

8. Starr, I., and Hildreth, E. A., The effect of aging and of the development of disease on the ballistocardiogram-a study of eighty subjects, originally healthy, followed from ten to fourteen years. Circulation, 1952, 5, 481.

9. Tanner, J. M., The construction of normal standards for cardiac output in man. J. Clin. Invest., 1949, 28, 567 . 
10. Scarborough, W. R., Personal communication.

11. Taylor, H. L., and Tiede, K., A comparison of the estimation of the basal cardiac output from a linear formula and the "cardiac index." J. Clin. Invest., 1952, 31, 209.

12. Starr, I., The ballistocardiograph—an instrument for clinical research and for routine clinical diagnosis. Harvey Lecture Series, 1947, 42, 194.
13. Ernsthausen, W., Reissmann, K., and von Wittern, W. W., Die Messung von Strömungsvorgängen in den herznahen Gefäben über die Rückwirkung der Blutbewegung auf den Körper. Pflügers Archiv, 1949, 251, 56.

14. Starr, I., Present status of the ballistocardiograph as a means of measuring cardiac output. Federation Proc., 1945, 4, 195. 